\title{
Intensification of drying process of wheat seeds based on differentiation of thermal energy supply
}

\author{
Kizurov Anatoly Sergeevich \\ Mechanics and Technology Institute \\ FSBEI HE Northern Trans-Ural SAU \\ Tyumen, Russia \\ Impossible_@mail.ru
}

\author{
Kokoshin Sergei Nikolaevich \\ Mechanics and Technology Institute \\ FSBEI HE Northern Trans-Ural SAU \\ Tyumen, Russia \\ kokoshinsn@gausz.ru
}

\begin{abstract}
Theoretical prerequisites for drying wheat seeds based on differentiation of the supply of thermal energy are presented. It is alternation of heating and cooling processes. In the structure of the theoretical premises, terms of efficiency of grain heating and efficiency of evaporation of surface moisture are introduced. To determine these coefficients, a methodology for experimental studies is presented, including laboratory equipment. The results of experimental studies and the prospects for the development of the topic are presented.
\end{abstract}

Keywords - wheat seed drying; differential drying; heat pump

\section{INTRODUCTION}

Modern technical means for removing excess moisture from colloidal bodies have passed a rather large path of development, ranging from the simplest devices to the newest complexes, working on hydrocarbon fuel, electric energy and using alternative sources of thermal energy [5].

However, there is a problem of drying seeds of agricultural crops, namely, the technical means used have a considerable physical wear and the incoming foreign equipment has a high productivity (from 8 to 100 tons / hour) which in its technical characteristics cannot withstand a "soft" drying regime great performance. In this regard, a problem situation has arisen, which consists in the following: on the one hand, there is a high demand for high-quality seeds; on the other hand, farms do not have the opportunity to obtain them on existing equipment [9].

Based on this, it was assumed that the use of a heat pump in a differentiated technological process would facilitate the use of "soft" drying regimes for grain seeds and other colloid bodies. In addition, when operating well-known equipment, a low level of automation and reliability is noted, namely, measurement humidity, temperature and level of accumulated material. Therefore, new technical solutions are needed to determine the initial characteristics of the grain material.

Thus, the development of an ecologically safe, resourcesaving way of drying seeds with a differentiated supply of heat, using the example of wheat, as part of the implementation of state programs aimed at resource saving and the development of agricultural science, is relevant.
The purpose of the work: intensification of the process of convective drying of wheat seeds in soft modes, using differentiation of the supply of thermal energy by a heat pump and improving the quality of the final product.

\section{THEORETICAL BACKGROUND}

The process of changing the grain temperature is described by the Newton-Richman expression from which an equation was derived that allows one to determine the time for heating or cooling $[2,4]$ :

$$
\tau=c \cdot M_{g} \cdot\left(T_{g}-T_{0}\right) / \alpha \cdot S \cdot\left(T_{a}-T_{g}\right)
$$

where $T_{0}$-the initial temperature of the grain, ${ }^{\circ} \mathrm{C}$;

$T_{g}$-the temperature of the grain, ${ }^{\circ} \mathrm{C}$;

$T_{a}$-the temperature of the agent, ${ }^{\circ} \mathrm{C}$.

The specific heat capacity of the grains is a function of its moisture content:

$c=f(u), J / k g \cdot K$,

where $u$ - the moisture content of the grains, $\%$.

The grain weight is also a function of humidity:

$M_{g}=f(u), k g$.

Consequently, the product of the specific heat per grain mass is a function of humidity:

$C g=c \cdot M g=f(u)$,

where $C g$ is the heat capacity of one grain, $\mathrm{J} / \mathrm{K}$.

Analysis of known literary sources made it possible to carry out a study of the effect of grain moisture on its heat capacity; for this purpose, the grain body was considered at the level of an elementary section representing alternation of layers possessing different physicochemical properties, the grain in the first assumption is a multilayer ellipsoid of revolution. To assess the thermophysical properties of the grains from a multilayer ellipsoid, an elementary region consisting of several elementary layers of different thickness and heat capacity was isolated. 


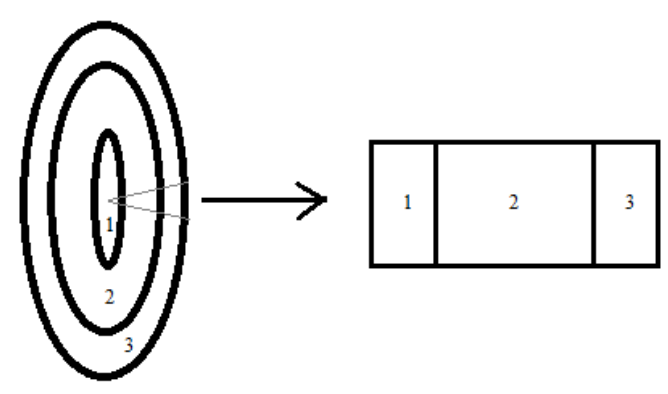

Fig. 1. Elementary plot of grain

For one grain, the dependence of heat capacity on the mass of thousands of grains and humidity was obtained:

$$
C_{g}=M_{1000} \cdot 10^{-6} \cdot(32.928 \cdot u \%+770.71 \pm 318.6)
$$

where $M_{1000}$ - weight of 1000 grains, g;

$u \%$ - moisture content in grains, $\%$.

In the drying process, the amount of moisture in the grains decreases, in connection with which, the mass of one grains and its moisture content decreases $[4,7,8]$ :

$$
m_{i}=\left(M_{1000} \cdot u_{0}\right)-m_{e v a} ; M_{g}=M+m .
$$

where $m_{\text {eva }}$ is the mass of evaporated moisture from one grain, g.

The solution of this system of equations (3) is the following system (4):

$$
M_{1000}=M_{1000}-m_{\text {eva }} \cdot 1000 \text {; }
$$

$$
u_{i}=\left(M_{1000} \cdot u_{0}-m_{e v a} \cdot 1000\right) /\left(M_{1000}-m_{e v a} \cdot 1000\right)
$$

Investigations of the influence of air humidity on the heat transfer coefficient using the similarity criteria were made. It was found that when drying wheat grains in the seed regime $\left(\mathrm{T}\right.$ agent $=0-80{ }^{\circ} \mathrm{C}, \mathrm{T}$ grain $\left.=0-45^{\circ} \mathrm{C}, \varphi=0-100 \%\right)$, the air humidity does not significantly change the heat transfer coefficient (maximum change at the boundary conditions of $8 \%)$.

Consequently, in the process of drying wheat grains in the seed regime, the coefficient of heat transfer from the agent to the grains can be determined from the equation [10]:

$$
\alpha=10^{-3} \cdot l^{-0.625} \cdot B_{W A}
$$

where $l$ - the hydraulic diameter of the cross-section of the grain, $\mathrm{m}^{2}$;

$B_{W A}=1.57 \cdot\left(T_{a}-T_{g}\right)^{0.125} \cdot X_{C}-$ introduced coefficient of moist air, taking into account the effect of surface temperature differences, J / s
$X_{C}=0.49635 \cdot\left(0.0148 \cdot T_{a}+11.234\right) /\left(0.9169-6 \cdot 10^{-5} \cdot T_{g}\right)-$ coefficient that takes into account the influence of the grain temperature on its heat capacity, relative units.

The influence of the temperatures of the agent and the grains on the coefficient of moist air $B_{W A}$ is reflected on the response surface (Figure 2), from which it can be seen that in the heating zone the coefficient $B_{W A}$, and hence the heat transfer coefficient $\alpha$, is more important than in the cooling zone.

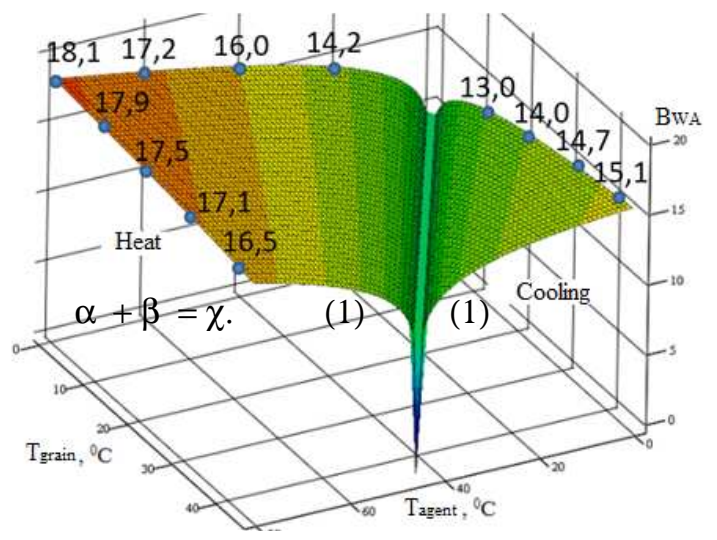

Fig. 2. The value of the coefficient of moist air, which takes into account the influence of the temperature differences of the BWA surfaces as a function of the temperature of the agent $\left(T_{a}=0 \ldots 80{ }^{\circ} \mathrm{C}\right)$ and grains $\left(T_{g}=0 \ldots 45^{\circ} \mathrm{C}\right)$

$$
\alpha+\beta=\chi \text {. }
$$

Assuming a uniform change in the temperature of the layer at various points, a heat balance system for the heating and cooling process is obtained for natural convection $[1,2,3,7]$ :

$$
\begin{gathered}
P= \pm 6.28 \cdot \pi \cdot 10^{-3} \cdot(2 \cdot l \cdot a /(l+a))^{-0.625} \cdot(5 \cdot a+6 \cdot b) / 60 \\
(1-(5 \cdot a+6 \cdot b) / 20) \cdot d T_{g}^{9 / 8} \cdot X_{C} ; \\
\alpha+\beta=\chi . \\
d u=100 \cdot\left(1-\left(M \cdot 10^{-8} u-d m\right) /\left(M \cdot 10^{-6}-d m\right)\right) \\
\alpha+\beta=\chi . \\
d m=\left(P \cdot \eta_{\text {eva }} \cdot d t\right) /\left(2502-2.4385 \cdot T_{g}\right) \\
d T_{g}=P \cdot \eta_{\text {heat }} \cdot d t / C_{g}
\end{gathered}
$$

where $P$-the input / output heat output, W;

$l, a, b$ - the length, width, thickness of the grain, respectively, $\mathrm{m}$;

$d T$-the temperature difference between the agent and the grains, ${ }^{\circ} \mathrm{C}$;

$T_{g}$-the grain temperature, ${ }^{\circ} \mathrm{C} ;$

$T_{a}$-the agent temperature, ${ }^{\circ} \mathrm{C}$;

$u$-the moisture content of the grains, $\%$;

$d m$-the change in the mass of the grain, $\mathrm{g}$;

$d t$-the change of time, s; 
$\eta_{\text {heat }}, \eta_{\text {eva }}$, - the efficiency of grain heating and evaporation of surface moisture, respectively, relative units.

To solve the system of equations (3), the algorithm presented in Fig. 3 was used [6].

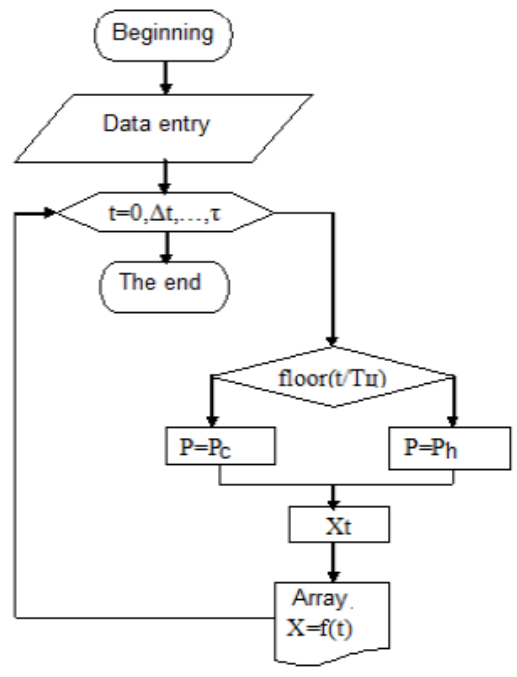

Fig. 3. Algorithm for solving systems of equations for differentiated drying kinetics

The algorithm of the solution implemented in the MathCAD software environment makes it possible to construct the temperature dependences $\mathrm{T}$ of grain $=\mathrm{f}(\mathrm{t})\left({ }^{\circ} \mathrm{C}\right)$, humidity $u=f(t)(\%)$ and moisture removal rate $d u / d t(\% / \mathrm{s})$ from wheat seeds from time $t$ (c) differentiated drying at the initial grain temperature $T_{0}=20{ }^{\circ} \mathrm{C}$, the temperature of the heating agent $T_{h}=40{ }^{\circ} \mathrm{C}$, the temperature of the cooling agent $T_{c}=5{ }^{\circ} \mathrm{C}$, the initial moisture content of the grains $u_{0}=24 \%$, the mass of thousands of grains $M=41 \mathrm{~g}$, heating / cooling $t=$ 60 s. (Figure 4) $[1,4,10]$.

This algorithm makes it possible to construct graphical dependences of the grain temperature $T$, humidity, drying rate $d u / d t$, the mass of thousands of grains $M$ on time, depending on the initial data $X_{0}$, which allowed to theoretically substantiate the soft drying regimes of wheat seeds with differentiated heat supply. Two efficiencies have been introduced into the structure of the solution: the evaporation of surface moisture evaporation $\left(\eta_{\text {eva }}\right)$, the grain heating efficiency $\left(\eta_{\text {heat }}\right)$, which allow to compare the theoretical and practical values of the efficiency coefficients obtained experimentally with a certain error (no more than $5 \%$ ).

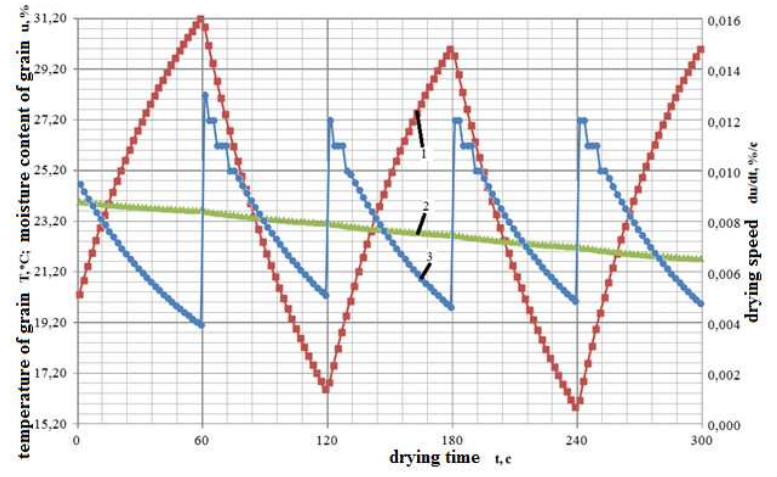

1 - change in grain temperature $T_{g}=f(t),{ }^{\circ} \mathrm{C} ; 2$ - change in humidity of the grain, $u=f(t), \% ; 3$ - speed of drying, $d u / d t, \% / \mathrm{s}$

Fig. 4. Dependences of grain temperature $T$, humidity $u$ of grain and moisture removal rate $d u / d t$ from wheat seeds versus time $t$.

\section{METHODOLOGY OF EXPERIMENTAL RESEARCH}

The program of experimental studies included the determination of the efficiency coefficients of heating and evaporation, which are parameters for optimizing the process of differentiated drying.

The purpose of the experiment was to study the regularities of the influence of soft regimes of drying wheat seeds with differentiated heat input on the efficiency of heating and the efficiency of evaporation of surface moisture.

Tasks are to:

-define the input parameters and their measurement ranges;

- conduct the ranking of input parameters;

-develop and compare with analogues a new technical tool for determining the moisture content of the grain;

-develop the methodology for constructing nomograms for determining the values of the efficiency of heating and the efficiency of evaporation by the input and output parameters of drying (the mass of thousands of grains, the initial and final moisture of the grain, the initial and final temperatures of grain and agents);

-develop a laboratory grain dryer on the basis of a heat pump and conduct studies on the intensification of the drying process of wheat seeds;

- reveal the interrelation of the efficiency factors in relation to the initial parameters of the grain material and the technological parameters of the differentiated drying;

-define qualitative indicators of wheat seeds before and after drying (infestation, germination and germination energy).

To conduct laboratory studies, a laboratory grain dryer was developed on the basis of a heat pump system, which makes it possible to carry out the differentiated kinetics of wheat grain drying. A sketch of a laboratory drier is shown in Figure 5. 


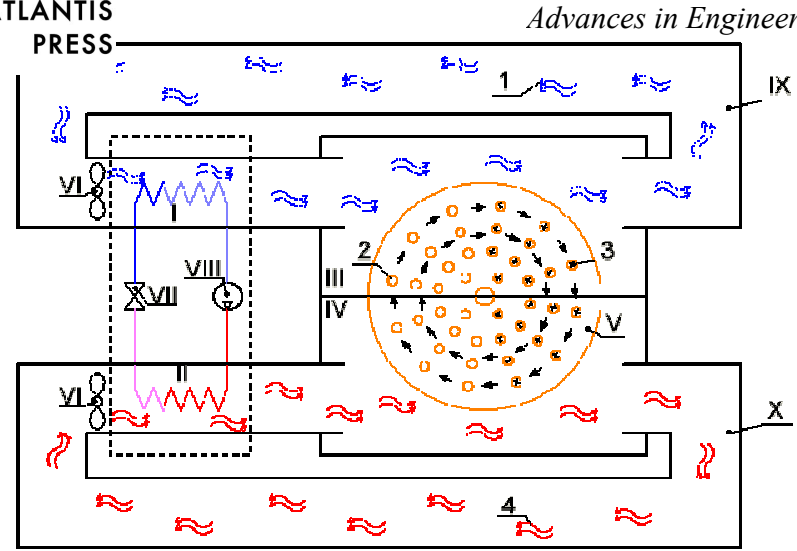

I - evaporator of the heat pump system (cooling); II - condenser of the heat pump system (heating); III - cooling chamber; IV - heating chamber; $\mathrm{V}$ - rotating tray for placing grain material; VI - recirculating axial fans; VII - throttle; VIII - the compressor; IX - air duct of the cooling agent; X - air duct of the heating agent;

1 - cooling agent; 2 - the cooled grain material; 3 - heated grain material; 4 - heating agent.

\section{Fig. 5. Sketch of a grain dryer in a laboratory (top view)}

The laboratory grain dryer was equipped with an automated control circuit, the elements of which are shown in Figure 6.
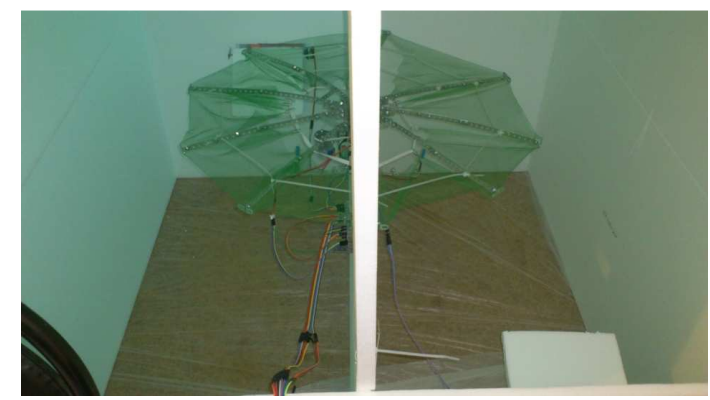

a

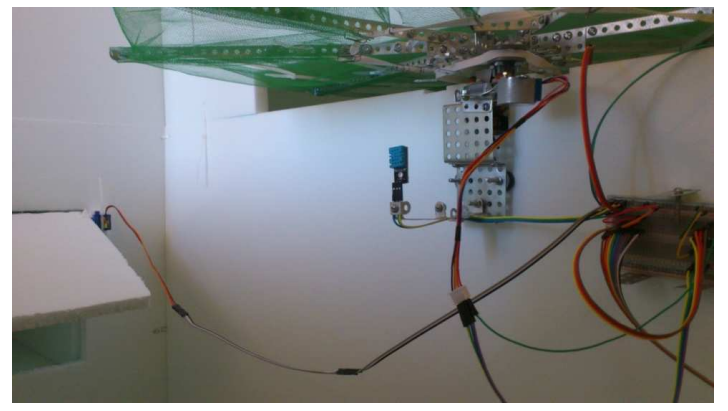

b

$\mathrm{a}$ - view inside; $\mathrm{b}$ - drive of the tray

Fig. 6. Laboratory dryers with automation elements (photo)

Prior to the planning of the experiment, the intervals for varying the drying kinetics parameters, such as the temperature and humidity of the heating and cooling agents, were evaluated $\left(T_{h}=37 \ldots 50{ }^{\circ} \mathrm{C}, T_{c}=13 \ldots 20{ }^{\circ} \mathrm{C}, \varphi_{h}=7 \ldots\right.$ $\left.12 \%, \varphi_{c}=20 \ldots 50 \%\right)$, the mass of a thousand grains $(M=36$ ... 40 grams $)$, the geometric parameters of the grain $(l=5.5 \ldots$ $7.5 \mathrm{~mm}, a=3.1 \ldots 3.4, b=2.7 \ldots 3.1)$, the initial moisture content of wheat grains $\left(u_{0}=19 \ldots 27 \%\right)$, the temperature of the grains $\left(T_{g}=9 \ldots 37{ }^{\circ} \mathrm{C}\right)$. To determine the ranges of the presented parameters, the following instruments and equipment were used (Fig. 7, 8): thermo-hygrometer ИВА-6; laboratory scales ВК-1500; callipers “ШЦ-II"; electromagnet Wile 55; sound scanner for determining the moisture content of the grain; Flir i5 thermal imager.

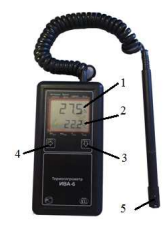

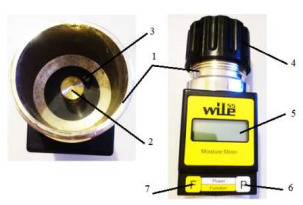

b

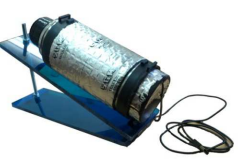

C $\mathrm{a}$ - thermohygrometer; $\mathrm{b}$ - moisture meter; $\mathrm{c}$ - sound scanner

Fig. 7. Devices and equipment for experimental research

The humidity-temperature characteristics of the heating and cooling agents are dependent on each other and the adjustment of one of the parameters leads to a change in the others, in this connection, it was decided to use the planning of a passive multi-factor experiment.

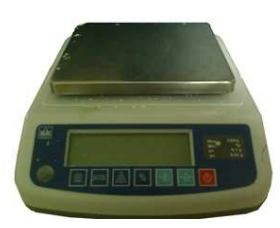

a

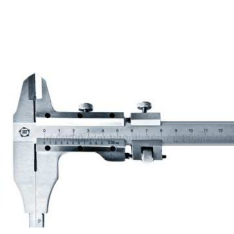

b

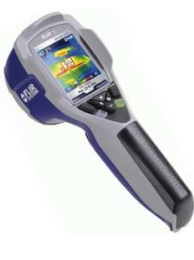

$\mathrm{c}$ a - scales; b - calipers; c - thermal imager

Fig. 8. Devices and equipment for conducting experimental studies (continued)

For the experiment, a passive multi-factor experiment was planned on the basis of factor ranking.

The parameters $x i$ and $X i$ were is input, and the parameters yi - output (figure 9) are displayed in detail on the block diagram.

Factors considered: $x l$ - temperature of heating agent $T$ heating; $x 2$ is the temperature of the cooling agent $T$ cooling; $x 3$ is the humidity of heating agent $\varphi$ of heating; $x 4$ is the humidity of the cooling agent; $x 5$ is the initial moisture content of grain $u_{0} ; \mathrm{x} 6$ is the initial grain temperature $T_{0} ; K 1$, $K 2$ - coefficient of heating of the grain $\eta$ heating and evaporation of surface moisture $\eta$ evaporation, respectively; $y 1, y 2$ - temperature and humidity of grain, respectively, at 360 seconds; $y 3, y 4$ - temperature and humidity of grain, respectively, at time $480 \mathrm{~s} ; y 5, y 6$ - temperature and humidity 
of grain, respectively, at time $600 \mathrm{~s} ; X 1$ - geometric characteristics of the grain $l, a, b ; X 2$ is the mass of a thousand grains of $M$.

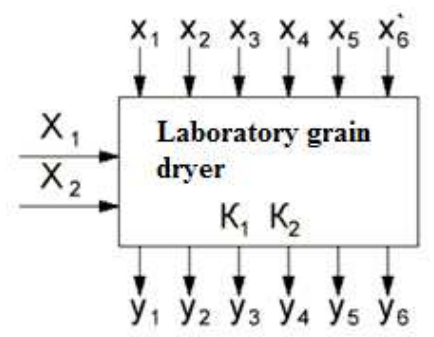

$X i$ - input parameters of grain material; $x i$ - input parameters of drying kinetics; $y i$ - output parameters of grain material; $K i$ - internal parameters

Fig. 9. Block diagram of the process of differentiated drying of wheat seeds

The experiments were carried out in the following sequence:

- determination of input parameters of grain material;

- determination of input parameters of drying kinetics;

- determination of output parameters of grain material;

- determination of internal parameters ( $\eta$ evaporation, $\eta$ heating) in a graphoanalytical way.

With the use of electronic weights BK-1500, according to the refined method, the mass of thousands of grains was determined.

According to the described method, geometric parameters of the grains were determined using the ШЦ-II caliper.

With the help of the Wile 55 moisture meter and the "Sound Scanner" technical tool developed at the Department "Power Supply to Agriculture" of the FSBEI HE Northern Trans-Ural SAU "[Sound Scanner for Determining the Parameters of Grain Crops / Utility Model RU 151089 U1], [" GrainSoundScan "/ Computer program - patent RU 2014614300], the initial moisture content of the grain sample was determined before and after drying. For the technical means of measuring the moisture content of the grain, the method of comparative tests of the Wile 55 moisture meter and the "Sound Scanner" is presented. The interface of the Grain Sound Scan program is shown in Figure 10.

Using the Flir i5 thermal imager, the grain temperatures before and after drying were determined.

After preparation, the heat pump plant of the laboratory grain dryer was started, in which two thermohygrometers were installed to record the temperatures and humidity of the agents in the heating chamber and the cooling chamber.

Investigated grain samples were placed on the movable tray and the tray moved from one chamber to another with an interval of 60 seconds. The first sample was removed from the grain dryer 360 seconds after the start, the second through 480, the third through 600. The samples after drying determined the temperature and humidity. All the data were recorded in Table 1 .

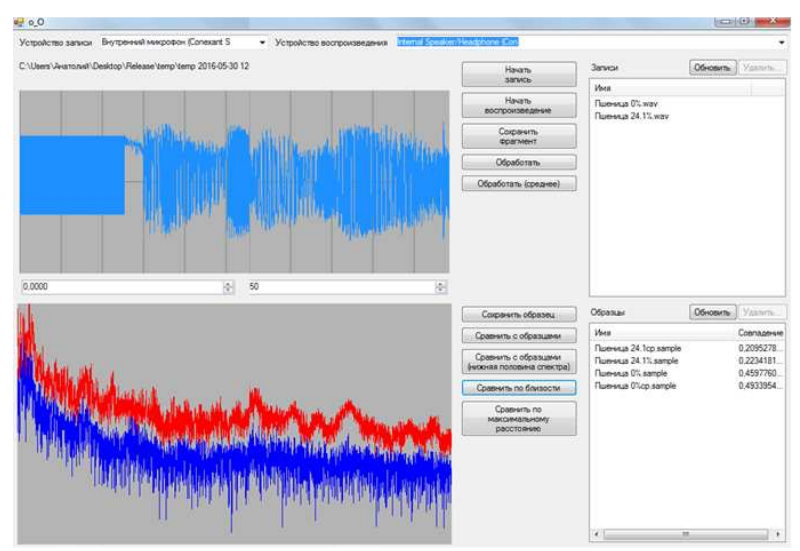

Fig. 10. GrainSoundScan interface

Based on the data on the developed methodology, nomograms were constructed in the MathCAD software environment for graphoanalytic determination of the heating and evaporation efficiency. As an example, Fig. 11 presents nomograms for the determination of the heating and evaporation coefficients at geometrical parameters of the grains $6.37 \times 3.27 \times 2.92 \mathrm{~mm}$, the mass of thousands of grains $M$ $=38.52 \mathrm{~g}$, the initial moisture content of the grain $u_{0}=22.3 \%$, the initial grain temperature $T_{0}=16.8{ }^{\circ} \mathrm{C}$, cooling agent temperature $T$ cooling $=13.6{ }^{\circ} \mathrm{C}$, heating agent temperature $T$ heating $=37.2^{\circ} \mathrm{C}$, cycle time $t$ cycle $=60 \mathrm{~s}$.

The output parameters and nomograms (Figure 11) determined the values of the heating and evaporation coefficients.

Then, the results of the experiments were processed to obtain regression equations 7 and 8:

$$
\begin{aligned}
& \eta_{\text {heat }}=f\left(T_{h}, \varphi_{h}, T_{c}, \varphi_{c}, u_{0}, T_{g}, u_{g}\right) ; \\
& \eta_{\text {eva }}=f\left(T_{h}, \varphi_{h}, T_{c}, \varphi_{c}, u_{0}, T_{g}, u_{g}\right) ;
\end{aligned}
$$

where $T_{h}, T_{c}, T_{g}$ - temperature of heating agent, cooling agent, grain after drying accordingly, ${ }^{\circ} \mathrm{C}$;

$\varphi_{h}, \varphi_{c}$ - humidity of the heating agent, cooling, respectively, \%;

$u_{0}, u_{g}$ - the initial grain moisture and after drying, respectively, $\%$.

A technique for determining regression coefficients is presented using application software packages in MathCAD and Excel environments.

The evaluation of the quality parameters of wheat seeds was carried out according to the known methods for determining the contamination, germination and energy of seed germination. 


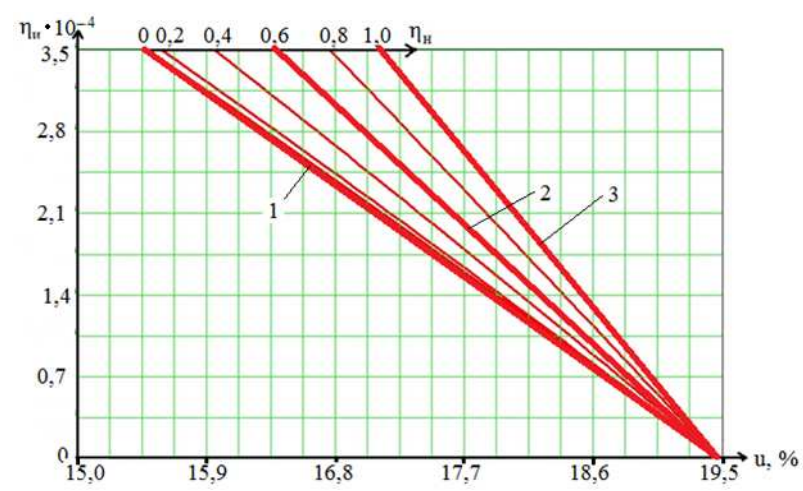

a - nomogram for determining the efficiency of evaporation of surface moisture;

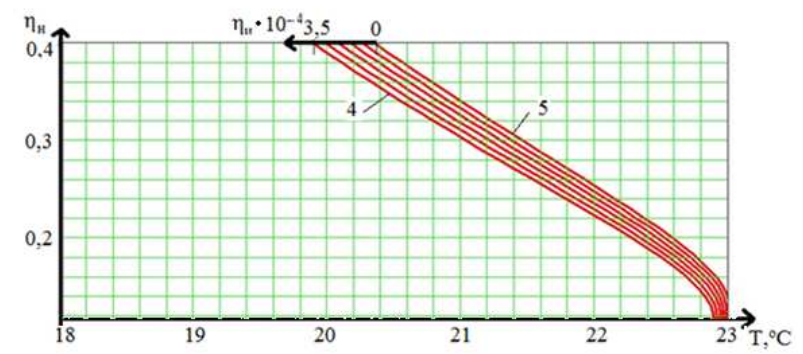

b - nomogram for determining the efficiency of grain heating;

1 - dependence of the change in the efficiency of evaporation of surface moisture on the final moisture content of the grains at a heating efficiency $\eta_{\text {heat }}=0$;

2 - dependence of the change in the efficiency of evaporation of surface moisture on the final moisture content of the grains at the efficiency of heating $\eta_{\text {heat }}=0.6$;

3 - dependence of the change in the efficiency of evaporation of surface moisture on the final moisture content of the grains at the efficiency of heating $\eta_{\text {heat }}=1$;

4 - dependence of the change in the efficiency of heating on the final temperature at an efficiency of evaporation of $\eta_{\text {eva }}=3.5 \cdot 10^{-4}$;

5 - dependence of the change in the efficiency of heating on the final temperature for the coefficient of efficiency of evaporation $\eta_{\text {eva }}=0$.

Fig. 11. Nomograms for determining the coefficients of heating and evaporation

Determination of energy costs for evaluating the drying process of wheat seeds with differentiated heat supply, including the determination of the productivity of a laboratory grain dryer and energy consumption for drying 1 planned kilogram of seeds, was carried out in accordance with the normative and technical documentation.

\section{RESULTS OF EXPERIMENTAL STUDIES}

The results of the ranking of the factors of experimental studies to determine the dependence of the efficiency of heating and evaporation are presented in Table 1.
TABLE I. EXPERIMENTAL RANKING OF EXPERIMENTAL FACTORS

\begin{tabular}{|l|c|c|c|c|c|c|}
\hline \multirow{2}{*}{ Names } & \multicolumn{6}{|c|}{ Factors } \\
\cline { 2 - 7 } & $\boldsymbol{T}_{\boldsymbol{h}}$ & $\boldsymbol{T}_{\boldsymbol{c}}$ & $\boldsymbol{T}_{\boldsymbol{0}}$ & $\boldsymbol{u}_{\boldsymbol{0}}$ & $\boldsymbol{\eta}_{\text {heat }}$ & $\boldsymbol{\eta}_{\text {eva }}$ \\
\hline $\begin{array}{l}\text { Deviation } T \\
\text { of grain, }{ }^{\circ} \mathrm{C}\end{array}$ & 3.97 & 17.93 & 0.02 & 0.94 & 11.35 & 0.19 \\
\hline $\begin{array}{l}\text { The } \\
\text { deviation } \\
\text { u, } \%\end{array}$ & 1.73 & 0.53 & 0.1 & 8.01 & 0.49 & 1.0 \\
\hline $\begin{array}{l}\text { Influence } \\
\text { on grain } T, \\
\text { place }\end{array}$ & 3 & 1 & 6 & 4 & 2 & 5 \\
\hline $\begin{array}{l}\text { Effect on } u, \\
\text { place }\end{array}$ & 2 & 4 & 6 & 1 & 5 & 3 \\
\hline $\begin{array}{l}\text { Average } \\
\text { influence } \\
\text { on } T \text { grains } \\
\text { and } u, \text { place }\end{array}$ & 1 & 1 & 4 & 1 & 2 & 3 \\
\hline $\begin{array}{l}\text { Factor code } \\
\text { (by } \\
\text { importance) }\end{array}$ & $x 1$ & $x 2$ & $x 3$ & $x 4$ & $x 5$ & $x 6$ \\
\hline
\end{tabular}

The results of comparative measurements of the moisture content of the grain material before and after drying with the aid of the Wile 55 moisture meter and the "Sound Scanner" hardware are shown in Figure 12.

The results of comparative tests showed that the rms deviation of the "Sound Scanner" is 0.002 , while for the Wile 55 moisture meter it is 0.009 to 0.042 , therefore, the measurement error of the "Sound Scanner" device is 4.5-21 times less than for Wile 55. Therefore the main measuring a device called "Sound Scanner" was chosen for the determination of humidity.

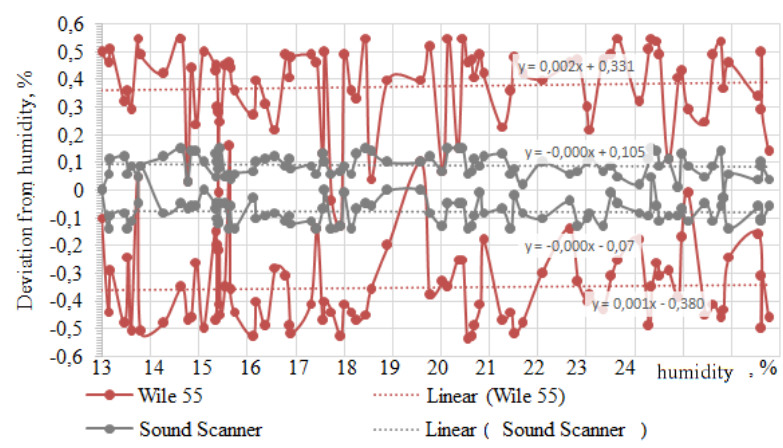

Fig. 12. Deviation of the readings of the moisture meter Wile 55 and "Sound scanner" when measuring the moisture content of wheat

Based on the results of experimental studies, the obtained data were processed using nomograms. The measurement evaluation showed that the obtained data are reliable at a significance level of $95 \%$.

The experimental studies of the input parameters on the efficiency coefficients of heating and evaporation made it possible to obtain regression equations for the estimation of the parameters for optimizing the efficiency of grain heating and the efficiency of evaporation of surface moisture:

$\eta_{\text {heat }}=10^{-3} \cdot\left(-11+1.351 \cdot T_{h}+5.457 \cdot \varphi_{h}-2.193 \cdot T_{c}-1.761 \cdot\right.$

$\left.\varphi_{c}+1.974 \cdot u_{0}\right)$ 
$\eta_{\text {eva }}=10^{-5} \cdot\left(-9.433-0.2585 \cdot T_{h}-7.911 \cdot \varphi_{h}+1.813 \cdot T_{c}+\right.$ $\left.1.500 \cdot \varphi_{c}+0.728 \cdot u_{0}\right)$

The adequacy of equations 9 and 10 is verified with the help of the Fisher criterion.

Analysis of equations 9 and 10 showed that the humidity of the heating agent has a significant effect on the efficiency of heating and evaporation, the temperature and humidity of the cooling agent are the second most important, and the initial moisture of the grain has a slight effect.

For the analysis of the obtained equations $(9,10)$ graphical dependences are constructed (Figure 13-16).
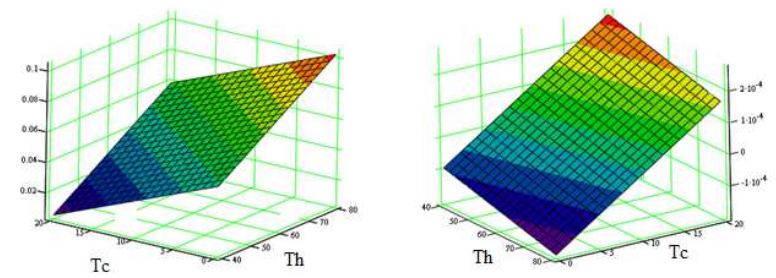

Fig. 13. The efficiency of heating and evaporation from the temperature of heating and cooling with the humidity of the heating agent $\varphi_{h}=50 \%$, the humidity of the cooling agent $\varphi_{c}=50 \%$, the humidity of the grains $u=20 \%$
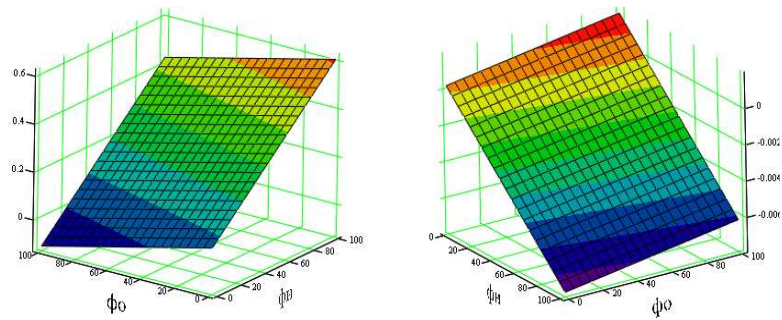

Fig. 14. The efficiency of heating and evaporation from the humidity of the heating agent and the cooling agent at the temperature of the heating agent $T_{h}$ $=60{ }^{\circ} \mathrm{C}$, the temperature of the cooling agent $T_{c}=10^{\circ} \mathrm{C}$, the humidity of the gravel $\mathrm{u}=20 \%$
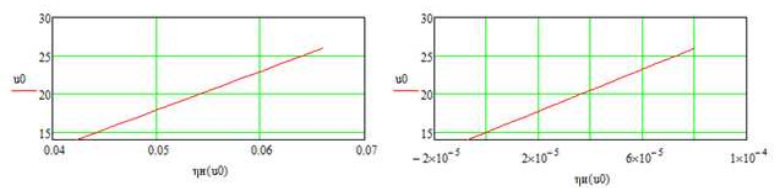

Fig. 15. The efficiency of heating and evaporation from the initial humidity of the grains at the temperature of the heating agent $T_{h}=60{ }^{\circ} \mathrm{C}$, the temperature of the cooling agent $T_{c}=10{ }^{\circ} \mathrm{C}$, the heating agent humidity of the heating agent $\varphi_{h}=50 \%$, the humidity of the cooling agent $\varphi_{c}=50 \%$

From the graphical dependencies (Figure 13-15) you can see:

-increase in the temperature of the heating agent is characterized by an increase in the efficiency of heating and a decrease in the efficiency of evaporation;

-decreasing the temperature of the cooling agent is characterized by an increase in the efficiency of heating and a decrease in the efficiency of evaporation;
- growth of humidity of the heating agent leads to an increase in the effipcier):y of hedting anfll to a decrease in the efficiency of evaporation;

-decreasing the humidity of the cooling agent leads to an increase in the efficiency of heating and a decrease in the efficiency of evaporation;

-increase in the initial moisture content of seeds is characterized by an increase in the efficiency of heating and evaporation.

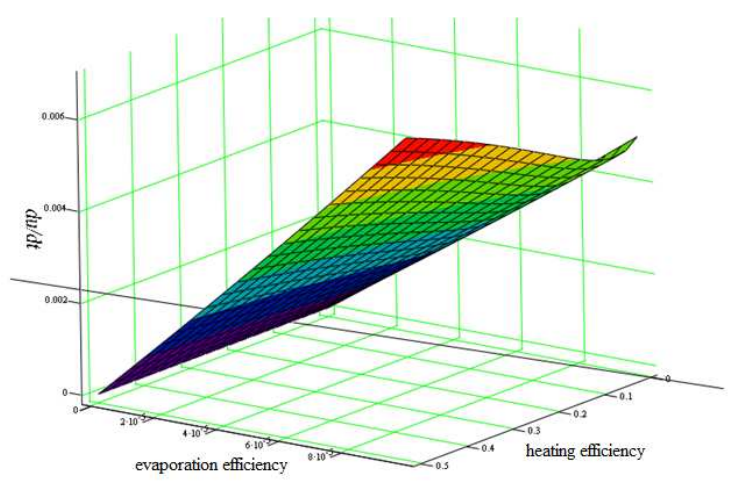

Fig. 16. Dependence of drying speed on heating efficiency and evaporation efficiency

Analysis of the dependence of drying rate on the efficiency of grain heating and evaporation of surface moisture (Fig. 16) shows that in the range $\eta_{\text {heat }}=0 \ldots 0.1$, the increase in the efficiency of heating leads to a decrease in the rate of drying. In addition, in the expressions for regressions (9) and (10), the temperature parameters have opposite signs, which means that with increasing the value of one of the efficiency factors with changing temperature parameters, the other will decrease.

Based on the results of determining the quality parameters of drying wheat seeds, the following results were obtained: after drying the seeds with a differentiated heat supply, the contamination is reduced by 2-3 times; germination energy was $62 \%$, germination - $89 \%$.

The results of determining the energy costs of the process of drying wheat seeds with a differentiated heat supply showed a $21 \%$ reduction in energy consumption of the process and a $28 \%$ increase in productivity.

\section{CONCLUSION}

Based on the results of theoretical and experimental research, the following conclusions were formulated:

- A mathematical model, an algorithm for calculating the cooling and heating processes are developed, analytical dependencies are obtained that allow to establish a soft regime for differentiated drying of wheat seeds by a heat pump. Analysis of theoretical studies has shown that the intensification of the process of differentiated grain drying is achieved by reducing the cooling / heating time to $60 \pm 15 \%$, reducing the efficiency of 
heating from 0.05 to 0.02 and increasing the efficiency of evaporation from $8.5 \cdot 10^{-5}$ to $27.5 \cdot 10^{-5}$.

- On the basis of theoretical and empirical studies, methods were developed and proposed using the graphical-analytical method that allowed determining the values of the coefficients of efficiency from nomograms in the MathCAD software environment (the efficiency of grain heating is from 0.02 to 0.05 ; the coefficient of useful effects of evaporation of surface moisture is from $8.5 \cdot 10^{-5}$ to $27.5 \cdot 10^{-5}$ ).

- A complex was developed and tested to determine the initial grain parameters and the efficiency of heating and evaporation, consisting of a laboratory grain dryer (RU 152192 U1) based on a heat pump and sound scanner (RU 151089 U1) with software (RU 2014614300). The operating conditions of the complex are justified (the temperature of the cooling agent is from +5 to $+15^{\circ} \mathrm{C}$, the temperature of the heating agent is +30 to $+75^{\circ} \mathrm{C}$, the time of the cooling / heating cycle is $60 \mathrm{~s} \pm 15 \%$ with the moisture content of the seed from 13 to $27 \%$ ). The standard deviation of humidity in the "Sound Scanner" is 0.002 , while for the Wile 55 moisture meter, it is from 0.009 to 0.042 . Therefore, the measurement error of the "Sound Scanner" device is 4.5-21 times less than for Wile 55 .

- It has been established that the proposed kinetics of drying has a positive effect on the qualitative characteristics of wheat seeds (after drying the seeds with a differentiated heat supply, the contamination is reduced 2-3 times, the germination energy is $62 \%$, the germination rate is $89 \%$ ).

\section{PROSPECTS FOR FURTHER DEVELOPMENT OF THE TOPIC}

In further scientific research on the topic of work, attention should be paid to:

- the effect of forced flows of heating agents and cooling agents;
- creation of an automatic control scheme, which determines the culture and initial data of the material coming in for drying;

- development of a heat pump system with the possibility of regulating independently the temperature parameters of heating and cooling agents in order to increase the efficiency of the system;

- development of the design of the industrial sample of a seed dryer on the basis of a heat pump system with a differentiated supply of thermal energy;

- expansion of the field of use of the developed kinetics of drying.

\section{References}

[1] N. Ben-Zeev, S. Zamenhof, "Effects of High Temperatures on Dry Seeds," Plant physiology, vol. 37, №6, pp. 696-708, April 1962.

[2] Colloid. Information on https://en.wikipedia.org/wiki/Colloid

[3] J Gutormson, Tim, Small Grains: Seed Size, 2018.

[4] Z. H. Zamaleev, V. N. Posokhin, V. M. Chefanov, Fundamentals of hydraulics and heat engineering: textbook, Publishing House "Doe", Saint-Petersburg, 2014.

[5] J.F. Harrington, Thumb rules of drying seeds, Crops \& Soils, Vol. 13, pp. 16-17, 1960.

[6] Floor and ceiling functions. Information on https://ru.wikipedia.org/wiki/ Floor_and_ceiling_functions

[7] A. Kizurov, I. lapshin, S. Kokoshin, "Differentiated drying of the mixtures colloidal components used in the construction of underground infrastructure," Procedia Engineering, vol.165, 2016, pp.806 - 816.

[8] J.L. Multon, Interactions between water and the constituents of grains, seeds and by-products. Preservation and Storage of Grains, Seeds and Their By- products, 2018.

[9] L. Andreev, V. Yurkin, "Energy efficient technologies of microclimate creation in animal husbandry," Proceedings of the International Conference "Actual Issues of Mechanical Engineering", 2017 (AIME 2017). doi:10.2991/aime-17.2017.11

[10] Physical properties of air. Information on http://www.highexpert.ru/content/gases/air.html 